\title{
Potential Mechanisms of Age Related SeVerity of COVID-19 INFECTION: IMPLICATIONS FOR DEVELOPMENT OF VACCINES, Convalescent SERUM, AND Antibody THERAPIES
}

\author{
A Preprint (Not Peer Reviewed)
}

\author{
Jiong Wang* \\ jiong_wang@urmc.rochester.edu
}

\author{
Martin S. Zand ${ }^{\ddagger}$ \\ martin_zand@urmc.rochester.edu
}

March 21, 2020

\begin{abstract}
There is an urgent need for vaccines to induce immunity to the 2019 coronavirus strain (COVID-19; CoV-SARS-2). Vaccine development may not be straightforward, in part due to the the phenomenon of antibody-dependent enhancement (ADE). The immune response to coronavirus infection or vaccination generates a mixture of IgG antibodies against viral surface proteins. Many of these antibodies block viral infection. However, in some cases IgG:virus complexes can facilitate viral entry and infection of cells by ADE, increasing the the risk and severity of infection. This phenomenon occurs in SARS, MERS, HIV, Zika and dengue virus infection and vaccination; it has been a serious barrier to vaccine development for these infections. Lack of high-affinity anti-COVID-19 IgG antibodies in children and younger adults may explain, in part, the decreased severity of infection in these groups. Here, we discuss the evidence for ADE in the context of COVID-19 infection, and how it may affect development of a vaccine and convalescent serum therapies. Here we discuss ADE in the context of COVID-19 infection, and how this may affect vaccine development, convalescent serum, and targeted monoclonal antibody therapies.
\end{abstract}

Keywords COVID-19 coronavirus $\cdot$ antibody-dependent enhancement $\cdot$ Fc receptor $\cdot$ vaccine $\cdot$ antibody

\section{Introduction}

The coronavirus infectious disease 2019 (COVID-19, CoVSARS-2) pandemic is currently an immense global health threat[1]. Estimates are that $14-20 \%$ of infected patients develop severe illness requiring hospitalization[2, 3, 4]. There are currently no effective treatments available, although there is a global rush to develop vaccines, small molecule inhibitors, and to test a variety of existing compounds for anti-viral activity. Approximately 5\% of those infected develop acute respiratory distress syndrome(ARDS), with high mortality. COVID-19 infection appears to occur at similar rates across age groups, al- though the severity of disease is less for those $<19$ years of age $[3,5]$. Interestingly, younger individuals are also known to lack or have a lower incidence of high affinity anti-CoV IgG. This is relevant as certain antibodies can potentiate, rather than protect against, $\mathrm{CoV}$ infection through antibody-dependent enhancement (ADE), wherein normal mechanisms of antigen-antibody complex clearance fail, and instead provide an alternate route for host cell infection[6]. These observations have serious implications for the development strategy of vaccines that induce anti-COVID-19 IgG antibodies. In this Viewpoint, we discuss the data underlying our concerns, and suggest strategies for assessing this risk, vaccine development and deployment.

\footnotetext{
${ }^{*}$ Department of Medicine, Division of Nephrology, University of Rochester Medical Center, 601 Elmwood Ave - Box 675, Rochester, NY USA 14618

${ }^{\dagger}$ University of Rochester Medical Center, Clinical and Translational Science Institute, 265 Crittendon Boulevard, Rochester NY, 14642. (585) 273-2819

${ }^{\ddagger}$ Corresponding author
} 


\section{Epidemiology of COVID-19 infection}

Initial data regarding the epidemiology of COVID-19 shows that individuals $\leq 19$ years of age accounted for $<3 \%$ of all confirmed cases[4,5]. Multiple reports have also indicated that individuals $\leq 19$ years old have milder symptoms, a lower hospitalization risk, and lower case fatality rates[2, 3, 4]. However, recent work by the Shenzhen Center for Disease Control, following 1286 close contacts of 391 index cases over a 28 day period, demonstrated that COVID-19 infection rates among close contacts $\leq 19$ years old were equivalent to those found in older cohorts[3] Importantly, this younger cohort was often asymptomatic $(<50 \%$ presenting with fever) and had less severe infection even when symptomatic. Similar patterns have been observed for the SARS [7] and MERS[8] coronaviruses, with a low incidence of symptomatic infection and fewer severe cases. Indeed, the inverse relationship of age and asymptomatic coronavirus infection with less pathogenic human strains (e.g. 229E, NL63, OC43) has been known for over a decade[9].

\section{Anti-CoV IgG levels in children and adults}

An important difference between children and adults is the presence of $\mathrm{IgG}$ antibodies directed at common circulating human coronavirus strains. Children lack anti-CoV IgG prior to 6 years of age, but then begin to develop antibodies against the common circulating strains in humans (229E, NL63, OC43, HKU1). The presence of such anti-CoV IgG increases with age, with several studies demonstrating high titers in people $>6$ years old[10]. There is also some evidence of cross-strain binding for anti-CoV IgG directed against the common strains circulating in humans[11]. Importantly, the anti-CoV IgG repertoire in children may consist of predominately low affinity $\mathrm{IgG}$, which will mature to high affinity anti-CoV IgG only after repeated infections.

\section{Antibody dependent enhancement in $\mathrm{CoV}$ infections}

Coronaviruses make use of antibody-dependent enhancement (ADE) of infection as an alternate mode of viral fusion with target cells[12, 13]. The coronavirus S (spike) protein contains a ligand binding domain, the angiotensin converting enzyme 2 (ACE2) protein for COVID-19 and SARS[14, 15], and dipeptidyl peptidase 4 (DDP4/CD26) for MERS[16]. Antibodies targeting the receptor binding sites can prevent $\mathrm{S}$-protein:ligand binding and potentially viral fusion[17, 18, 19]. However, anti-S protein IgG complexed with virus will cause uptake of the virus-IgG complex via the Fc family of receptors[20], and subsequent viral fusion with macrophages, B cells, monocytes (FcR $\gamma$ family), and vascular endothelium via the neonatal Fc receptor (nFcR) [21, 12]. Binding of complement to antigen-antibody complexes formed by IgG1 and IgG3 may also be a mechanism for ADE. Normally a mechanism for viral clearance and antigen presentation, phagocytosis now becomes another route for viral infection. This mechanism is well known for other viruses, including respiratory syncitial (RSV), HIV, and dengue virus (DENV)[20].

For SARS and COVID-19, the protein sequences responsible for ADE have been identified on the S protein (Figure 1) [22]. Importantly, sera from SARS patients contain a mixture of IgG antibodies that can both inhibit $\mathrm{CoV}$ infection and cause ADE[23]. Similarly, vaccination with recombinant S protein can elicit both inhibitory IgG antibodies in animal models, as well as antibodies responsible for $\mathrm{ADE}[22]$. Even the presence of neutralizing antibodies can cause severe disease. Anti-S protein:CoV complexes have been linked to increased cytokine release (e.g. MCP-1 and IL-8) in lung macrophages, and cytokine storm syndrome[24].

Pre-existing anti-CoV IgG antibodies to common strains of $\mathrm{CoV}$ that infect humans, but also react with COVID19 and induce ADE, could be another risk factor for severe disease[13]. This is a well described phenomenon for DENV, where antibodies against one strain are a risk factor for severe disease during infection with another DENV strain[25], and anti-DENV IgG appears to potentiate Zika virus infection via ADE[26]. While high affnity anti-CoV IgG may be most effective in neutralizing $\mathrm{CoV}$ during infection[27], it may also increase risk for ADE. This is not a hypothetical concern. Clinical trial results for vaccines against DENV and RSV halted the development of these vaccines when they potentiated the severity of infection[28, 29]. ADE has thus been a major barrier to development of HIV, Zika Virus, and DENV vaccines[30, 31, 32].

\section{Can lack of high affinity anti-CoV IgG explain less severe infections in children?}

These findings suggest at least three mechanisms that may contribute to decreased severity of COVID-19 in subjects $\leq 20$ years of age. At the time of infection, the absence or lower concentrations of high affinity, cross-reactive, anti-CoV antibodies capable of inducing ADE may contribute to lower viral loads and more rapid clearance of CoV. This may include a shift to CD8 T cell and NK cell mediated viral clearance. Secondly, the development of high-affinity, class switched IgG antibodies generally requires multiple rounds of antigenic exposure (e.g. priming and boosting). Even those antibodies that emerge during the immune response after the first exposure to will initially be of lower affinity. Finally, ADE has been linked to the development of cytokine storm syndrome, which occurs in the most severe cases of MERS, SARS and COVID-19 infection[6, 23]. Thus, absence of high affinity anti-CoV IgG could potentially mitigate infection severity, and potentially explain the milder disease in children and younger adults. Further work will need to be done to assess this hypothesis. 
Consensus:

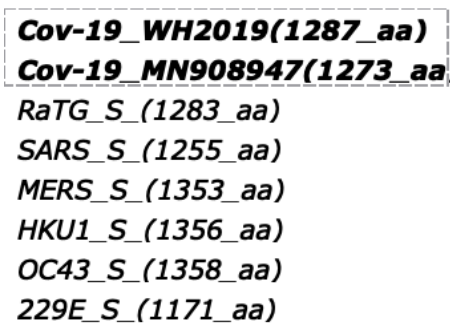

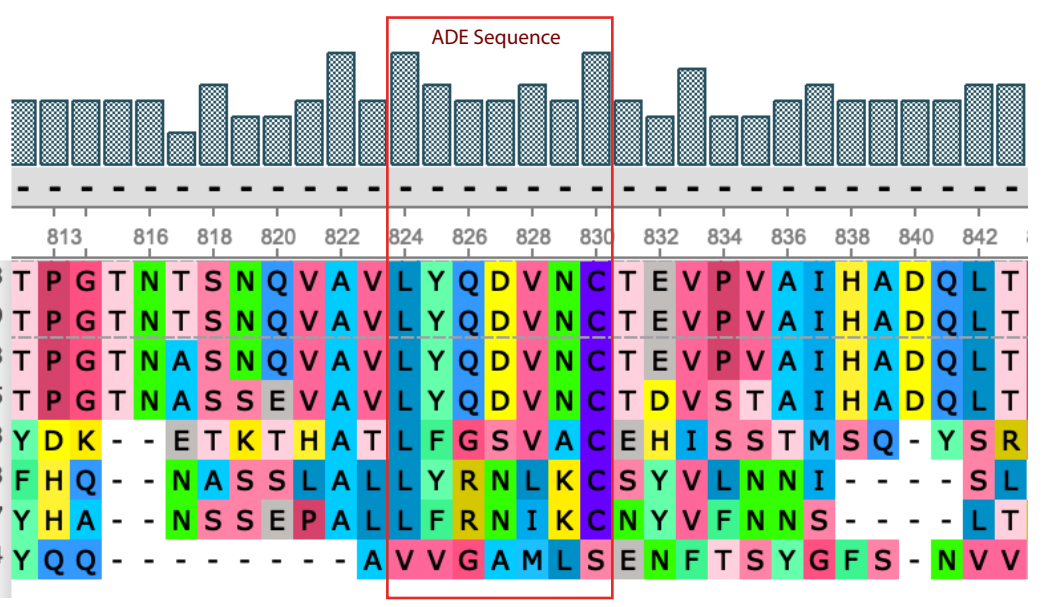

Figure 1. ADE associated CoV spike protein sequences.. The antibody-dependent enhancement (ADE) associated spike glycoprotein peptide sequences $\mathrm{S}_{579-603}$ from SARS[22] are also conserved in two COVID-19 strains (isolates in bold) and the closely related bat coronavirus strain (RaTG). There is less sequence homology in the same S protein region of MERS or the common human coronavirus strains (HKU1, OC43, 229E). Sequence homologies analyzed with the Clustal Omega method using Unipro UGENE v33.0 software.

\section{Implications for convalescent serum and monoclonal antibody therapy}

The potential for ADE has implications for the use of convalescent sera or targeted monoclonal antibody therapies for treatment of COVID-19, which are being discussed as potential therapies and for clinical trials[33]. The hypothesis is that such sera or antibodies may improve infection morbidity and mortality, if given early enough in the course of COVID-19 illness. This is based on reports of the presence of neutralizing antibodies in the sera of individuals who have recovered from COVID-19 infection[34]. As noted above, such sera may also contain antibodies that induce antibody-dependent enhancement of COVID-19 infection. Neutralizing antibodies in sera have also been associated with worse a worse prognosis in some individuals with SARS[35]. Similar phenomena could also occur with targeted monoclonal antibodies[30, 36, 37]. This suggest that any wide-spread use of convalescent sera or monoclonal antibodies should take this possibility into account, and perhaps include screening for ADE in vitro in therapeutic preparations.

\section{Implications for vaccine development}

The above data suggest that development of a COVID-19 vaccine will require careful design and testing to assure both efficacy and safety. There are several vaccine types currently being pursued for COVID-19 including: mRNA DNA, recombinant protein, virus-like particle, and liveattenuated or killed virus. With the potential exception of live, attenuated virus vaccines, the general goal is to induce adaptive immune response resulting in high affinity IgG against $\mathrm{S}$ or $\mathrm{N}$ viral capsid proteins. However, unless care is taken to modify the protein sequences to remove or inactivate regions highly associated with ADE, if this is even possible, we may produce vaccines that enhance, rather than protect against, severe COVID-19 infection. This could be particularly problematic in children, with their reduced risk of severe infection.

Given these issues, we suggest several considerations for vaccine development (Table 1). First, the immunodominance of various antibody subsets should be assessed carefully for all COVID-19 vaccines. This should include identifying mapping epitope targets to COVID-19 protein sites, especially those known to induce ADE. Next, clinical trials will need to be designed to specifically look for ADE in vaccine recipients who are subsequently infected. This should include pre- and post- vaccination measurement of anti-COVID-19 reactive IgG. Additional in vitro and in vivo testing of vaccine recipient sera for ability to induce ADE should be performed. Given the incidence of milder disease in younger individuals, and the potential for increasing the risk of ADE in vaccinated children subsequently infected with COVID-19, initial clinical trials should consider carefully whether to include children.

Importantly, long term follow-up of vaccinated cohorts will be essential to assess both vaccine efficacy and increased risk of ADE. This should include monitoring of the broad anti-CoV IgG repertoire to further aid in the design of future coronavirus vaccines. We will likely need to track the proportion of protective versus ADE inducing antibodies generated by each vaccine. This may vary by due to a variety of factors, including HLA type, vaccine adjuvant, vaccine protein glycosylation, and prior exposure to other $\mathrm{CoV}$ strains. Multiplex methods developed for influenza can be quickly adapted to this use[38]. This may lead to further modifications vaccine antigens to alter or eliminate sequences associated with ADE. This may become even 
more critical as the current human coronavirus mutates or becomes seasonal.

\section{Table 1. Considerations for COVID-19 vaccine} development

\begin{tabular}{l}
\hline Screen for pre-vaccine anti-COVID-19 IgG \\
Identify immunodominant epitope targets \\
Test post-vaccine sera for ADE potential \\
Restrict initial vaccine trials to adults \\
Long-term follow-up of vaccinated subjects \\
Multiplex measurement of CoV IgG cross-reactivity \\
\hline
\end{tabular}

Similar issues may emerge with use of convalescent sera to treat COVID-19 infection, especially with hyper-immune serum vaccinated individuals, and with targeted monoclonal antibodies. It may be prudent to asses for ADE inducing antibodies in convalescent sera and therapeutic monoclonal antibodies prepared for clinical administration. Given the paucity of data on this issue, further work will needed to rigorously determine whether this is indeed a significant issue.

The current urgency for COVID-19 therapies has brought together the scientific community to find treatments. In our rush to develop vaccines and antibody-based therapies, we should be mindful of what we have learned about ADE from SARS, HIV, and dengue virus research. A rapid and careful approach to vaccine and therapeutic

\section{Contributors}

JW and MZ conceived and wrote the manuscript, JW created the figure and performed the sequence analysis.

\section{Disclosure}

The authors have no competing interests to declare.

\section{Revision History}

- Initial Posting - March 17, 2020

- Revision 1 (March 18,2020) - Minor formatting and added page header denoting pre-print status

- Revision 2 (March 21,2020) - Added more recent US data and references specific to COVID-19 induced ADE mechanism. Added discussion of targeted monoclonal antibody therapies and ADE.

\section{Acknowledgment}

This work was supported by the National Institutes of Health Institute of Allergy, Immunology and Infectious Diseases grant R21 AI138500, and the University of Rochester Clinical and Translational Science Award UL1 TR002001 from the National Center for Advancing Translational Sciences. The content is solely the responsibility of the authors and does not necessarily represent the official views of the National Institutes of Health. None of the above funders had any role in the decision to publish or preparation of the manuscript.

\section{References}

[1] Sohrabi C, Alsafi Z, O’Neill N, Khan M, Kerwan A, Al-Jabir A, et al. World Health Organization declares Global Emergency: A review of the 2019 Novel Coronavirus (COVID-19) [Journal Article]. Int J Surg. 2020;76:71 - 76. Available from: https: //www.ncbi.nlm.nih.gov/pubmed/32112977.

[2] The Novel Coronavirus Pneumonia Emergency Response Epidemiology T. The Epidemiological Characteristics of an Outbreak of 2019 Novel Coronavirus Diseases (COVID-19) China, 2020 [Journal Article]. China CDC Weekly. 2020;2(8):113-122. Available from: http://weekly.chinacdc.cn//article/id/ e53946e2-c6c4-41e9-9a9b-fea8db1a8f51.

[3] Bi Q, Wu Y, Mei S, Ye C, Zou X, Zhang Z, et al. Epidemiology and Transmission of COVID-19 in Shenzhen China: Analysis of 391 cases and 1,286 of their close contacts [Journal Article]. medRxiv. 2020;p. 2020.03.03.20028423. Available from: https://www.medrxiv.org/content/ medrxiv/early/2020/03/04/2020.03.03. 20028423.full.pdf.

[4] Wu Z, McGoogan JM. Characteristics of and Important Lessons From the Coronavirus Disease 2019 (COVID-19) Outbreak in China: Summary of a Report of 72 Cases From the Chinese Center for Disease Control and Prevention. JAMA. 2020 02;Available from: https://doi.org/10.1001/ jama.2020.2648.

[5] COVID-19 Response Team C. Severe Outcomes Among Patients with Coronavirus Disease 2019 (COVID-19) - United States;69.

[6] Tetro JA. Is COVID-19 receiving ADE from other coronaviruses? [Journal Article]. Microbes Infect. 2020;Available from: https://www.ncbi. nlm.nih.gov/pubmed/32092539.

[7] Chan-Yeung M, Xu RH. SARS: epidemiology [Journal Article]. Respirology. 2003;8 Suppl:S914. Available from: https://www.ncbi.nlm.nih. gov/pubmed/15018127.

[8] Memish ZA, Al-Tawfiq JA, Assiri A, AlRabiah FA, Al Hajjar S, Albarrak A, et al. Middle East respiratory syndrome coronavirus disease in children [Journal Article]. Pediatr Infect Dis J. 2014;33(9):9046. Available from: https://www.ncbi.nlm.nih. gov/pubmed/24763193.

[9] van der Zalm MM, van Ewijk BE, Wilbrink B, Uiterwaal CSPM, Wolfs TFW, van der Ent CK. Respiratory Pathogens in Children with and without 
Respiratory Symptoms [Journal Article]. The Journal of Pediatrics. 2009;154(3):396 - 400.e1. Available from: http://www.sciencedirect.com/ science/article/pii/S0022347608007191.

[10] Zhou W, Wang W, Wang H, Lu R, Tan W. First infection by all four non-severe acute respiratory syndrome human coronaviruses takes place during childhood [Journal Article]. BMC Infectious Diseases. 2013;13(1):433. Available from: https:// doi .org/10.1186/1471-2334-13-433https : //bmcinfectdis.biomedcentral.com/track/ pdf/10.1186/1471-2334-13-433.

[11] Maache M, Komurian-Pradel F, Rajoharison A, Perret M, Berland JL, Pouzol S, et al. Falsepositive results in a recombinant severe acute respiratory syndrome-associated coronavirus (SARS$\mathrm{CoV}$ ) nucleocapsid-based western blot assay were rectified by the use of two subunits ( $\mathrm{S} 1$ and $\mathrm{S} 2$ ) of spike for detection of antibody to SARS-CoV [Journal Article]. Clin Vaccine Immunol. 2006;13(3):40914. Available from: https://www.ncbi.nlm.nih. gov/pubmed/16522785.

[12] Wang SF, Tseng SP, Yen CH, Yang JY, Tsao CH, Shen CW, et al. Antibody-dependent SARS coronavirus infection is mediated by antibodies against spike proteins [Journal Article]. Biochem Biophys Res Commun. 2014;451(2):208-14. Available from: https://www.ncbi.nlm.nih.gov/ pubmed/25073113.

[13] Wan Y, Shang J, Sun S, Tai W, Chen J, Geng Q, et al. Molecular Mechanism for Antibody-Dependent Enhancement of Coronavirus Entry. Journal of Virology. 2020;94(5). Available from: https://jvi. asm. org/content/94/5/e02015-19.

[14] Wong SK, Li W, Moore MJ, Choe H, Farzan M. A 193-amino acid fragment of the SARS coronavirus $\mathrm{S}$ protein efficiently binds angiotensinconverting enzyme 2 [Journal Article]. J Biol Chem. 2003;279:3197. Available from: https : //www . jbc . org/content/279/5/3197.full.pdf.

[15] Yan R, Zhang Y, Li Y, Xia L, Guo Y, Zhou Q. Structural basis for the recognition of the SARS-CoV-2 by full-length human ACE2 [Journal Article]. Science. 2020;Available from: https://www.ncbi. nlm.nih.gov/pubmed/32132184.

[16] Kannan S, Shaik Syed Ali P, Sheeza A, Hemalatha K. COVID-19 (Novel Coronavirus 2019) - recent trends [Journal Article]. Eur Rev Med Pharmacol Sci. 2020;24(4):2006-2011. Available from: https : //www.ncbi.nlm.nih.gov/pubmed/32141569.

[17] Tian X, Li C, Huang A, Xia S, Lu S, Shi Z, et al. Potent binding of 2019 novel coronavirus spike protein by a SARS coronavirus-specific human monoclonal antibody [Journal Article]. Emerg Microbes Infect. 2020;9(1):382-385. Available from: https : //www.ncbi.nlm.nih.gov/pubmed/32065055.
[18] Zhou H, Chen Y, Zhang S, Niu P, Qin K, Jia $\mathrm{W}$, et al. Structural definition of a neutralization epitope on the N-terminal domain of MERS-CoV spike glycoprotein [Journal Article]. Nat Commun. 2019;10(1):3068. Available from: https://www . ncbi.nlm.nih.gov/pubmed/31296843.

[19] Du L, Zhao G, Yang Y, Qiu H, Wang L, Kou $\mathrm{Z}$, et al. A conformation-dependent neutralizing monoclonal antibody specifically targeting receptorbinding domain in Middle East respiratory syndrome coronavirus spike protein [Journal Article]. J Virol. 2014;88(12):7045-53. Available from: https : //www.ncbi.nlm.nih.gov/pubmed/24719424.

[20] Taylor A, Foo SS, Bruzzone R, Dinh LV, King NJ, Mahalingam S. Fc receptors in antibody-dependent enhancement of viral infections [Journal Article]. Immunol Rev. 2015;268(1):340. Available from: https://onlinelibrary.wiley.com/doi/ full/10.1111/imr.12367?sid=nlm\%3Apubmed.

[21] Tirado SMC, Yoon KJ. Antibody-dependent enhancement of virus infection and disease [Journal Article]. Viral Immunol. 2003;16:69.

[22] Wang Q, Zhang L, Kuwahara K, Li L, Liu Z, Li $\mathrm{T}$, et al. Immunodominant SARS Coronavirus Epitopes in Humans Elicited both Enhancing and Neutralizing Effects on Infection in Non-human Primates [Journal Article]. ACS Infect Dis. 2016;2(5):36176. Available from: https://www.ncbi.nlm.nih. gov/pubmed/27627203.

[23] Jaume M, Yip MS, Cheung CY, Leung HL, Li $\mathrm{PH}$, Kien $\mathrm{F}$, et al. Anti-severe acute respiratory syndrome coronavirus spike antibodies trigger infection of human immune cells via a $\mathrm{pH}$ and cysteine protease-independent FcgammaR pathway [Journal Article]. J Virol. 2011;85(20):1058297. Available from: https://www.ncbi.nlm.nih. gov/pubmed/21775467.

[24] Li X, Geng M, Peng Y, Meng L, Lu S. Molecular immune pathogenesis and diagnosis of COVID19. Journal of Pharmaceutical Analysis. 2020;Available from: http://www.sciencedirect.com/ science/article/pii/S2095177920302045.

[25] Dejnirattisai W, Jumnainsong A, Onsirisakul N, Fitton P, Vasanawathana S, Limpitikul W, et al. CrossReacting Antibodies Enhance Dengue Virus Infection in Humans. Science. 2010;328(5979):745-748. Available from: https://science.sciencemag. org/content/328/5979/745.

[26] Khandia R, Munjal A, Dhama K, Karthik K, Tiwari R, Malik YS, et al. Modulation of Dengue/Zika Virus Pathogenicity by Antibody-Dependent Enhancement and Strategies to Protect Against Enhancement in Zika Virus Infection [Journal Article]. Front Immunol. 2018;9:597. Available from: https : //www . ncbi.nlm.nih.gov/pubmed/29740424. 
[27] Rani M, Bolles M, Donaldson EF, Van Blarcom T, Baric R, Iverson B, et al. Increased Antibody Affinity Confers Broad In Vitro Protection against Escape Mutants of Severe Acute Respiratory Syndrome Coronavirus. Journal of Virology. 2012;86(17):91139121. Available from: https://jvi.asm.org/ content/86/17/9113.

[28] Halstead SB. Dengvaxia sensitizes seronegatives to vaccine enhanced disease regardless of age. Vaccine. 2017;35(47):6355 - 6358. Available from: http://www.sciencedirect.com/ science/article/pii/S0264410X17313610.

[29] Kim HW, Canchola JG, Brandt CD, Pyles G, Chanock RM, Jensen K, et al. Respiratory syncytial virus disease in infants despite prior administration of antigenic inactivated vaccine. American Journal of Epidemiology. 1969 04;89(4):422434. Available from: https://doi org/10.1093/ oxfordjournals.aje.a120955.

[30] Winarski KL, Tang J, Klenow L, Lee J, Coyle EM, Manischewitz J, et al. Antibody-dependent enhancement of influenza disease promoted by increase in hemagglutinin stem flexibility and virus fusion kinetics. Proceedings of the National Academy of Sciences. 2019;116(30):15194-15199. Available from: https://www.pnas.org/content/ 116/30/15194.

[31] Brown JA, Singh G, Acklin JA, Lee S, Duehr JE, Chokola AN, et al. Dengue Virus Immunity Increases Zika Virus-Induced Damage during Pregnancy [Journal Article]. Immunity. 2019;50(3):751-762.e5.

[32] Mascola JR, Mathieson BJ, Zack PM, Walker MC, Halstead SB, Burke DS. Summary report: workshop on the potential risks of antibody-dependent enhancement in human HIV vaccine trials [Journal Article]. AIDS Res Hum Retroviruses. 1993;9(12):117584. Available from: https://www.ncbi.nlm.nih. gov/pubmed/7908211.
[33] Casadevall A, anne Pirofski L. The convalescent sera option for containing COVID-19. The Journal of Clinical Investigation. 2020 3;130(4). Available from: https://www.jci.org/articles/view/ 138003.

[34] Mair-Jenkins J, Saavedra-Campos M, Baillie JK, Cleary P, Khaw FM, Lim WS, et al. The Effectiveness of Convalescent Plasma and Hyperimmune Immunoglobulin for the Treatment of Severe Acute Respiratory Infections of Viral Etiology: A Systematic Review and Exploratory Meta-analysis. The Journal of Infectious Diseases. 2014 07;211(1):8090. Available from: https://doi.org/10.1093/ infdis/jiu396.

[35] Ho MS, Chen WJ, Chen HY, Lin SF, Wang MC, Di $J$, et al. Neutralizing antibody response and SARS severity [Journal Article]. Emerg Infect Dis. 2005;11(11):1730-7. Available from: https:// wWw.ncbi.nlm.nih.gov/pubmed/16318725.

[36] Frei JC, Wirchnianski AS, Govero J, Vergnolle O, Dowd KA, Pierson TC, et al. Engineered Dengue Virus Domain III Proteins Elicit Cross-Neutralizing Antibody Responses in Mice [Journal Article]. J Virol. 2018;92(18).

[37] Wang Q, Zhang L, Kuwahara K, Li L, Liu Z, Li $\mathrm{T}$, et al. Immunodominant SARS Coronavirus Epitopes in Humans Elicited both Enhancing and Neutralizing Effects on Infection in Non-human Primates [Journal Article]. ACS Infect Dis. 2016;2(5):36176. Available from: https://www.ncbi.nlm.nih. gov/pubmed/27627203.

[38] Wang J, Wiltse A, Zand MS. A Complex Dance: Measuring the Multidimensional Worlds of Influenza Virus Evolution and Anti-Influenza Immune Responses. Pathogens. 2019;8(4). Available from: https : / www .mdpi.com/2076-0817/8/4/238. 